\title{
The JAK/STAT signaling cascade in gastric carcinoma (Review)
}

\author{
PUJA KHANNA, PEI JOU CHUA, BOON HUAT BAY and GYEONG HUN BAEG \\ Department of Anatomy, Yong Loo Lin School of Medicine, \\ National University of Singapore, Singapore 117 597, Republic of Singapore
}

Received July 6, 2015; Accepted August 3, 2015

DOI: $10.3892 /$ ijo.2015.3160

\begin{abstract}
Gastric carcinoma remains one of the most prevalent forms of cancer worldwide, despite the decline in incidence rates, increased awareness of the disease and advancement in treatment strategies. Helicobacter pylori infection, dietary factors, lifestyle influences and various genetic aberrations have been shown to contribute to the development and progression of gastric cancer. Recent studies on the genomic landscape of gastric adenocarcinoma have identified several key signaling molecules, including epidermal growth factor receptor family (ErbB) members, vascular endothelial growth factor receptor family (VEGFR) members and PI3K/Akt/mTOR pathway components, that have been implicated in the molecular pathogenesis of gastric cancers. However, clinical trials with compounds that target these molecules have failed to show a significant improvement in overall survival rates when supplemented with conventional therapies. Therefore, it is essential to identify effective prognostic and/or diagnostic biomarkers and develop molecular targeted therapies. The JAK/STAT cascade is a principal signal transduction pathway in cytokine and growth factor signaling, regulating various cellular processes such as cell proliferation, differentiation, migration and survival. Numerous in vivo and in vitro studies have shown that dysregulated JAK/STAT signaling is a driving force in the pathogenesis of various solid cancers as well as hematopoietic malignancies. Hence, a large number of preclinical and clinical studies of drugs targeting this pathway are currently underway. Notably, aberrant JAK/STAT signaling has also been implicated in gastric cancers. In this review, we focus on the ongoing research on the JAK/STAT cascade in gastric carcinoma and discuss the therapeutic potential of targeting JAK/STAT signaling for the treatment of gastric cancer.
\end{abstract}

Correspondence to: Dr Gyeong Hun Baeg, Department of Anatomy, Yong Loo Lin School of Medicine, National University of Singapore, 4 Medical Drive, MD10, Singapore 117 597, Republic of Singapore

E-mail: antbgh@nus.edu.sg

Key words: gastric carcinoma, JAK/STAT signaling pathway, STAT3, prognostic marker, targeted treatment

\section{Contents}

1. Introduction

2. Gastric tumorigenesis

3. JAK/STAT signaling in gastric tumorigenesis

4. Conclusion

\section{Introduction}

Gastric cancer refers to a group of heterogeneous malignant tumors arising in any part of the stomach, with the potential to spread through the blood/lymph vessels to other tissues of the body. Gastric carcinoma continues to be one of the most predominant forms of cancer worldwide (1). Approximately 952,000 new cases of gastric cancer were reported in the year 2012 , accounting for $6.8 \%$ of all cancers, and thus, making it the fifth most common cancer in the world (2). The incidence rates of gastric cancer are particularly high in East Asia, South America and East Europe, whereas lowest incidence rates prevail in North America, Africa and Eastern Mediterranean region (2). These regional differences reflect variations in dietary patterns and food habits, as well as the prevalence of Helicobacter pylori infection (3). Furthermore, gastric cancer accounted for 723,000 deaths in 2012, making it the third most common cause of death in both genders (4). Although the incidence of gastric carcinoma is declining, the mortality rates are alarming and the need of the hour is to develop specific and efficacious treatment options in the effort to combat this dreaded disease.

\section{Gastric tumorigenesis}

Gastric carcinoma: etiology and risk factors. The stomach is a part of the alimentary tract, which aids in the digestion of food by secreting hydrochloric acid and enzymes. Histologically, the stomach contains four distinct layers with the innermost layer (mucosa) containing the gastric glands (5). The most common form of gastric cancer (90-95\%) is adenocarcinoma, which arises from the glandular epithelium of the innermost lining of the stomach (6). Less common forms of gastric cancer include lymphoma of the stomach, gastrointestinal stromal tumor and gastrointestinal carcinoid tumor. Approximately 4\% of all gastric cancer cases are of the lymphoma type arising from immune cells found in the wall of the stomach $(7,8)$. On the other hand, gastrointestinal stromal tumor is a rare benign or 
malignant tumor arising in the connective tissue of the stomach (8). Gastrointestinal carcinoid tumor is a neuroendocrine tumor of hormone-forming cells in the stomach, accounting for around 3\% of all gastric cancers (9).

Under the Lauren classification, gastric carcinoma can manifest as two main histologic forms, intestinal type or diffuse type (10-12). The intestinal type of gastric carcinoma is well differentiated with cells arranged in glandular/tubular structures, whereas the diffuse type comprises of scattered poorly cohesive cells with little or no gland formation. In certain cases, the stomach tumor may exhibit features of both cancer types (10). The Ming system of classification of gastric carcinomas is based on the growth pattern of neoplastic cells, and categorizes tumors into expanding type or infiltrative type $(13,14)$. More recently, the WHO system of classification which has also been adopted, grades adenocarcinomas on the basis of the extent of metaplastic intestinal tissue. Under this classification system, five subtypes namely adenocarcinoma (intestinal and diffuse), papillary, tubular, mucinous and signet-ring cell are identified (6)

Since gastric cancers grow slowly, the initial cancer stages are asymptomatic and generally remain undetected (15). However, the extent of the tumor as well as outcome of disease is determined by the initial cancer-causing event. There are numerous risk factors associated with gastric cancer, ranging from Helicobacter pylori (H. pylori) infection to age, gender, geographical location and other lifestyle factors (16). Infection by $H$. pylori is the primary risk factor for gastric cancers, specifically for those arising from the distal portion of the stomach. H. pylori promotes gastric inflammation, clinically known as chronic atrophic gastritis, which subsequently leads to cancerous alterations to the lining of the stomach (17).

Gastric carcinoma occurs more commonly in older people, primarily above the age of 60 . A combination of aging with $H$. pylori infection may have an additive role in the promotion of gastric carcinoma, and people having been exposed to H.pylori infection in childhood are at a high risk of developing adult gastric cancer $(18,19)$. Concurrently, studies have shown that men are at a higher risk of developing gastric carcinoma as compared to women; particularly for $H$. pylori-induced gastric cancer, due to lifestyle disparities as well as estrogenmediated biological differences $(7,20)$. Geographical features also dictate incidence rates, with higher number of cases seen in East Asia, Eastern Europe and parts of South and Central America and lower rates seen in Northern and Western Africa, South Central Asia, and North America (21). Histologically, the diffuse type of gastric adenocarcinoma is uniformly distributed amongst populations while the intestinal type of gastric cancer is predominantly found in the high risk geographical regions (11). Interestingly, there is also a variation seen in the incidence rates between different ethnic groups living in the same region (22).

Furthermore, a low socioeconomic status has been associated with a high risk of developing gastric cancer (23). Diets including high intake of salt and preserved or pickled food also increase the chances of a person developing gastric cancer, and studies have shown that eating fresh vegetables and fruits may help lower these risk rates $(19,24)$. Lifestyle factors including smoking has also been associated with gastric cancers, partic- ularly of those arising in the upper portion of the stomach (7). An overview of gastric carcinogenesis is illustrated in Fig. 1.

Genetic aberrations and mutations associated with gastric cancer. In addition to the risk factors, studies on the genomic landscape of gastric adenocarcinoma have revealed that certain genetic alterations and/or mutations can contribute to the pathogenesis of gastric cancer (25). Advancement in molecular profiling technologies have enabled rapid whole genome sequencing, with better resolution that provides researchers the opportunity to scan for known genomic mutations, as well as identify novel genomic aberrations specific to different subsets of gastric carcinoma patients (26-28).

A high throughput screen has been conducted using 237 gastric adenocarcinoma patient tissues that led to the identification of 474 'hotspot' mutations in 41 genes (29). Specifically, it was found that $34(14.4 \%)$ of 237 gastric cancer patients harbour mutations in PlK3CA (5.1\%), TP53 (4.6\%), APC (2.5\%), STK11 (2.1\%), CTNNB1 (1.7\%) and CDKN2A (0.8\%) (29). Another study using 15 adenocarcinoma patient tissues along with matched normal tissues has identified somatic mutations in TP53 (11/15), PIK3CA (3/15) and ARIDIA (3/15) (30). Dulak et al also carried out genomic profiling analysis of 486 gastrointestinal cancers, including 296 esophageal and gastric cancers, and identified 64 regions of recurrent amplified/deleted somatic mutations (33). Amplified genes that were identified included kinases such as ERBB2, FGFR1, FGFR2, $E G F R$, and $M E T$, as well as several novel genes not previously known to be associated with carcinogenesis were recognized. All these studies provided a foundation for the development of novel treatment options, specifically targeting genes with 'hotspot' mutations in gastric cancer. Since targeted therapy offers several advantages over the traditionally available treatment alternatives, many researchers are currently working on translating these genomic findings to clinical outcomes (Fig. 2).

Molecular profiling has shown that the most frequently mutated genes in gastric cancer patients are the members of epidermal growth factor receptor family (ErbB1-4). Of these, overexpressed ErbB1 has been implicated in 27-64\% of gastric cancer patients (31-33). However, clinical trials where cetruximab, a monoclonal anti-EGFR antibody, was used along with capecitabine-cisplatin to treat patients with advanced gastric cancer have failed to demonstrate a significant improvement (34). On the other hand, 6-34\% of gastric cancer patients showed increased levels of ErbB2/HER2, primarily encompassing those belonging to the intestinal type of tumor $(35,36)$. In the ToGA trial, the inclusion of trastuzumab (an anti-HER2 monoclonal antibody) to traditional chemotherapy treatment showed a slight increase in overall survival (OS) from 11.1 to 13.8 months in patients with HER2 amplified gastric adenocarcinomas; therefore, providing the potential of molecular targeted therapy in the treatment of gastric cancer (37). Overexpression of ErbB3 has been reported to be associated with tumor progression/invasion and lower OS rates in gastric cancer patients (38). Analysis of gastric cancer tissues has shown that significantly higher levels of HER2 and HER3 are associated with late stage gastric adenocarcinoma (stage III-IV) compared to stage I-II disease (22-24\% vs. $5.8 \%-7.7 \%$, $\mathrm{p}<0.05)$ (39). Several ongoing clinical trials are currently 


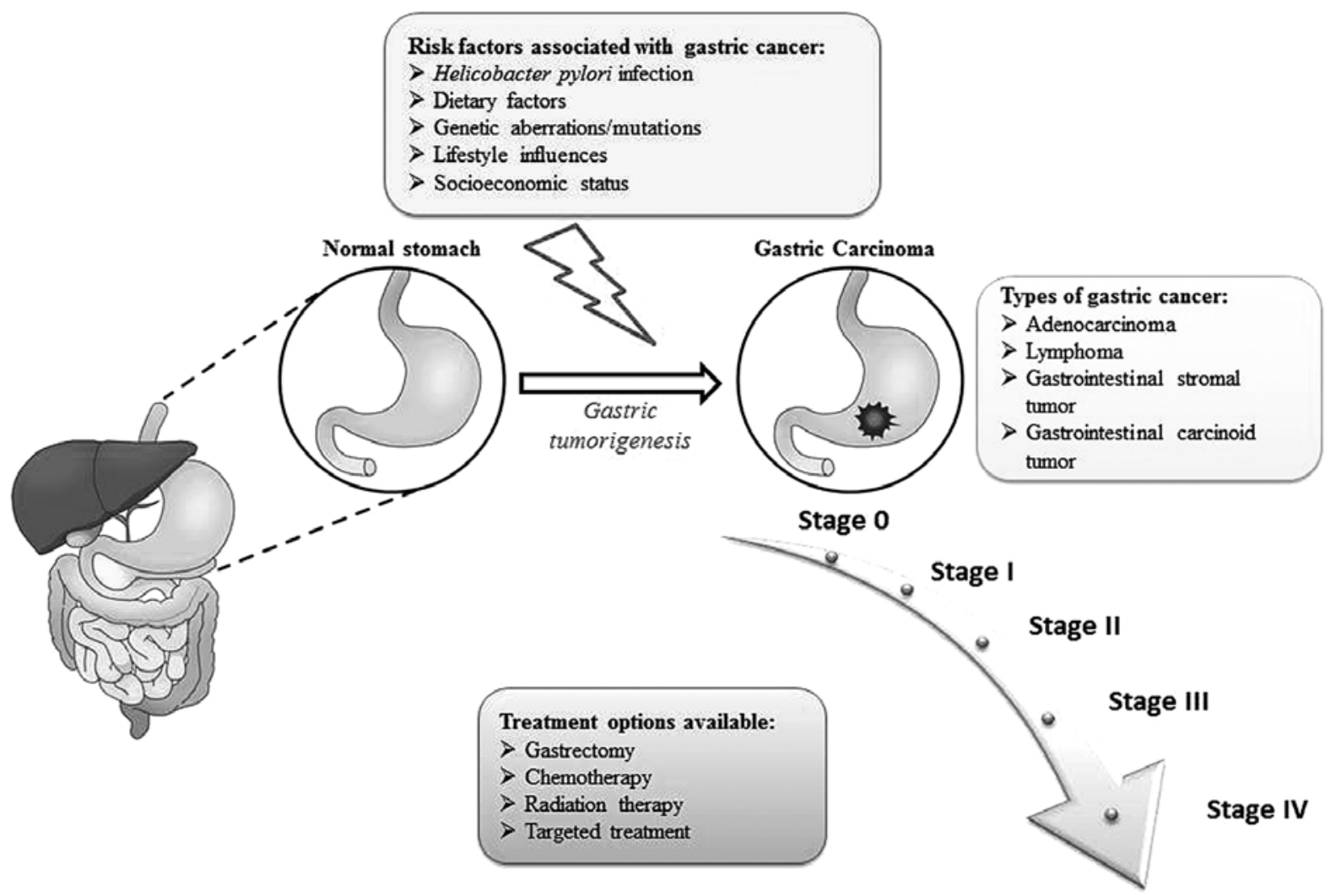

Figure 1. Gastric cancer: risk factors, types and treatment options available.

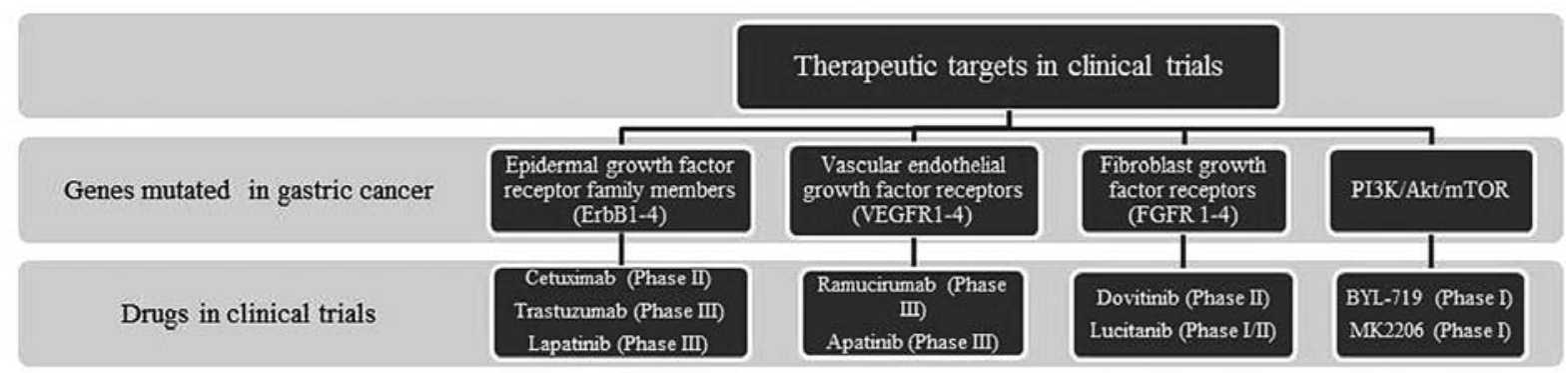

Figure 2. Genetic mutations associated with gastric cancer, and representative drugs currently in clinical trials. A complete list of drugs can be found on ClinicalTrials.gov.

evaluating the efficacy of novel EGFR-targeted treatment options in HER-2 positive/amplified gastric cancers, as well as on EGFR and HER2 co-expressing tumors (40).

An increased expression of vascular endothelial growth factor (VEGF) and vascular endothelial growth factor receptors (VEGFR1-4) is known to promote angiogenesis, and is therefore associated with more aggressive forms of gastric cancer (41-43). Despite promising in vitro results, clinical trials with the VEGF-A monoclonal antibody bevacizumab failed to show a significant improvement in patient survival rates when supplemented with first-line chemotherapy $(44,45)$. On the other hand, the results from the REGARD clinical trial with ramucirumab, (an anti-VEGFR monoclonal antibody) showed an increase in OS rates (5.2 versus 3.8 months, $\mathrm{p}=0.047$ ) in patients with advanced gastric cancer after first-line chemotherapy (46).
Fibroblast growth factor receptors (FGFR1-4), another family of receptor tyrosine kinases, have also been implicated in gastric carcinoma (26). Five to eight percent of gastric patients show amplified $F G F R 2$ contributing to lymph node metastasis, and thus, worsening the prognosis (47). Consequently, the clinical studies of dovitinib targeting this amplified FGFR 2 are currently under phase II clinical trials as a monotherapy in patients with metastatic or unresectable gastric cancer (48).

The PI3K/Akt/mTOR is a major effector cascade of receptor tyrosine kinase signaling, and the core components of this cascade are found to be altered in gastric carcinoma. PIK3CA is found to be mutated in 5\% of gastric cancers in which mutation of this gene leads to the constitutive activation of the pathway even in the absence of ligand $(29,49,50)$. Poor prognosis has also been associated with gastric cancer 
patients having amplified PIK3CA in advanced gastric cancer cases (51). Several clinical trials targeting molecules involved in this dysregulated signaling pathway are under investigation. Everolimus, an mTOR inhibitor, has increased progression-free survival in neuroendocrine tumors and renal cell carcinomas; however, it failed to show a significant improvement in survival rates when tested for its efficacy in previously treated advanced gastric carcinoma patients $(52,53)$. Phase I trials in gastric cancer patients with altered PIK3CA or amplified HER2 are being tested with the isoform specific p110- $\alpha$ inhibitor BYL719 and the heat shock protein 90 (Hsp90) inhibitor AUY922 (NCT01613950) (54). The Akt inhibitor MK2206 is also in early clinical trials for patients with gastric cancer, as well as other solid tumors (NCT01260701, NCT00963547) (54).

The treatment of early stage gastric cancer primarily includes radiation therapy/chemotherapy to reduce tumor size followed by surgical removal of the tumor mass (55). Advanced forms of gastric carcinoma are, however, more difficult to target. Several genetic alterations have been shown to be associated with gastric cancer; and thus, researchers have been trying to develop therapeutic interventions targeting these signaling molecules as a novel therapeutic approach to eradicate these aggressive forms of stomach cancer. Although targeted therapeutics against the molecules with 'hotspot'mutations have provided the potential to treat patients with gastric cancer, ongoing clinical trials with the drugs have failed to show a significant improvement in overall survival rates of patients. Therefore, more effective and promising therapeutics targeting additional molecules implicated in gastric cancer need to be designed and developed.

\section{JAK/STAT signaling in gastric tumorigenesis}

JAK/STAT signal transduction pathway. The JAK/STAT (Janus kinase/signal transducer and activator of transcription) cascade is a principal signal transduction pathway that is involved in a range of physiological and cellular processes, such as cellular proliferation, stem cell self-renewal and immune responses (56-58). Tightly regulated JAK/STAT signaling is of utmost importance in maintaining normal cellular homeostasis. Consequently, dysregulation of this pathway is known to be associated with a variety of pathological conditions, including immune disorders and human cancers (59).

The JAK/STAT signaling cascade is highly conserved across phyla, ranging from slime molds to humans (59). The JAK/STAT cascade was originally identified in the context of interferon- $\alpha$ (IFN $\alpha$ ), IFN- $\gamma$ and interleukin-6 (IL-6)-mediated signaling. The binding of these immune modulators to their receptors triggers the activation and dimerization of specific receptors, which in turn, causes the receptor-associated JAKs to come into close proximity, and subsequently leads to the auto- and/or trans-phosphorylation of the kinases (60). The cognate receptor then becomes phosphorylated by the activated JAKs and in turn, serves as a docking site for the SH2 domaincontaining STAT molecules (5). STATs, which have been tyrosine-phosphorylated by JAK kinases are released from the receptor, dimerize and then translocate to the nucleus, where they act as a transcription factor to modulate the expression of downstream target genes (56). This cascade is negatively regulated by three main classes of molecules; namely protein tyrosine phosphatase (PTP), suppressor of cytokine signaling (SOCS) and protein inhibitor of activated STAT (PIAS), at different levels of signaling (62). PTPs dephosphorylate STAT, JAK or the associated receptors, consequently, inactivating them, whereas PIAS molecules inhibit the signaling by preventing activated STAT dimers from binding to their downstream targets or by interfering with their transactivation capacity (61). SOCS molecules interfere with STAT recruitment to the receptor, inhibit JAK activation, or promote the proteasomal degradation of activated JAKs or the associated receptors. Interestingly, SOCS is transcriptionally regulated by JAK/STAT signaling, and thus a negative feedback mechanism occurs (62).

In mammals, the JAK family includes four members, namely JAK1, JAK2, JAK3 and TYK2. JAK1, JAK2 and TYK2 are known to be ubiquitously expressed, whereas JAK3 expression is restricted to the hematopoietic cells, suggesting its essential role in hematopoietic development (63). On the other hand, the STAT protein family has 7 key players namely STAT1, STAT2, STAT3, STAT4, STAT5A, STAT5B and STAT6, each of which is known to regulate diverse cellular processes (56). STAT proteins act as important transcription factors that regulate the transcription of many key molecules involved in cell differentiation, proliferation, inflammation and apoptosis. Recently, an indirect transcriptional role of STAT has been reported, and this non-canonical JAK/STAT signaling has been shown to be associated with heterochromatin stability and the epigenetic regulation of global transcriptional state, particularly by DNA methylation and chromatin remodelling (64).

Constitutive activation of JAK/STAT signaling is wellestablished in cancers. It may occur as a result of an increased cytokine/cytokine receptor production or a decreased expression of the negative regulators of the pathway (65). Activating somatic mutations in JAK2 or MPL (encoding thrombopoietin receptor) have been implicated in certain cases of myeloproliferative disorders, resulting in the persistent activation of STAT3/5 $(66,67)$. In-frame deletions in gp130 were shown to lead to the constitutive activation of STAT3, even in the absence of a ligand during the pathogenesis of hepatocellular carcinomas (68). Furthermore, sphingosine-1-phosphate receptor-1 (S1PR1) was reported to upregulate JAK2/STAT3 signaling in different epithelial cancers via increasing STAT3 signaling, which in turn transcriptionally regulates itself, SIPRI and IL-6 gene in a positive feed forward loop, contributing to the process of tumorigenesis in these cancers (69). Novel somatic mutations in $L N K$, encoding a negative regulator of the JAK/STAT pathway, was also found to be a driving force in a subset of myeloproliferative neoplasms by activating STAT signaling (70). Additionally, the tumor suppressor PTP delta, which is known to dephosphorylate STAT3, was found to be frequently mutated in human glioblastoma, head and neck cancers and lung cancers, thus, reinforcing the causative role of dysregulated STAT signaling in a wide variety of cancers (71).

The first report describing STAT3 as an oncogene was published more than a decade ago. Constitutively-active STAT3 produced by substituting two cysteine residues for alanine and asparagine respectively, in the C-terminal loop of the $\mathrm{SH} 2$ domain was demonstrated to have the ability to transform immortalized fibroblasts and induce tumors in nude 
mice (72). This study provided the foundation for exploring the role of STAT3 as an oncogene in various human cancers. Subsequent studies have linked dysregulated JAK/STAT signaling to the tumor initiation and progression of a variety of solid cancers and hematopoietic malignancies (66-69). STAT3 has been shown to prevent apoptosis by increasing the expression levels of the anti-apoptotic proteins of Bcl-2 family proteins (73). In particular, STAT3 mediates its pro-survival functions via Survivin, which not only prevents apoptosis but also promotes the mitogenic activity of cells $(73,74)$. Studies have also shown that STAT3 controls the expression of the master EMT (epithelial-to-mesenchymal) transcriptional regulators, thus, contributing to the process of metastasis in cancers (75). An aberrant expression of STAT3 was also shown to contribute to the tumor progression via facilitating cell motility and invasion (76). Moreover, STAT3 is also known to promote the formation of new blood vessels by increasing the levels of VEGF and hypoxia-inducible factor (HIF)-1 $\alpha$ (77-79). Several immunomodulatory molecules are also regulated by the JAK/STAT cascade. Specifically, reduced Th1-dominated antitumor response on aberrant STAT3 activation contributes to cancer cell survival and proliferation, suggesting the role of STAT3 in the maintenance of the tumor microenvironment by contributing to the process of inflammation and angiogenesis $(77,80-82)$

JAK-STAT signaling in gastric carcinoma. Various in vitro and in vivo studies have implicated dysregulated JAK/STAT signaling in haematological malignancies, as well as in various solid cancers. Interestingly, aberrant activation of the JAK/STAT pathway has also been described to contribute to the process of gastric tumorigenesis $(83,84)$. Constitutivelyactive STAT3 was found in various gastric cancer cell lines, such that its inhibition by the ectopic expression of dominant negative STAT3 or JAK inhibitor induced the apoptosis of these cancer cells. Inhibition of STAT3 has consistently resulted in a significant decrease in the levels of the anti-apoptotic protein Survivin, leading to a decrease in gastric cancer cell survival (85). Gong et al examined 86 cases of resected gastric cancers to study the association of activated STAT3 with various angiogenesis factors, including VEGF expression and microvessel density in gastric cancer. Univariate survival analysis confirmed the role of aberrant STAT3 levels in angiogenesis, which in turn, was found to contribute to the gastric cancer progression (79). Furthermore, the expression of REG I $\alpha$ (a member of the regenerating gene family), an IL-6 inducible protein, was examined in cancer specimens to study the significance of STAT3 in inflammation-driven gastric cancer. REG I $\alpha$ expression was found to correlate with phospho-STAT3 expression in gastric cancer tissues, suggesting the role of REG I $\alpha$ in tumorigenesis by promoting anti-apoptosis (86). Moreover, in the gp130 $157 \mathrm{FF}$ mouse model of gastric cancer, IL-6/IL-11-dependent increase of STAT3 expression was shown to contribute to the development and progression of $H$. pylori-associated gastric adenocarcinoma (87).

One hundred gastric adenocarcinoma patient tissues after gastrectomy were also analysed to examine the expression of STAT3 by immunohistochemical staining (88). It was found that STAT3 expression was highly associated with
TNM staging and survival, thus, suggesting that it functions as a biomarker predicting poor prognosis of gastric cancer. Similarly, Deng et al evaluated the association of STAT3, phospho-STAT3, SOCS1 as well as other clinicopathological factors with overall survival rates in 53 gastric cancer patient tissue samples. Univariate and multivariate analysis revealed that phospho-STAT3 and lymph node metastasis are independent predictors of OS in gastric cancer, and STAT3 expression correlates with lymph node metastasis status in these patients (89). Deng et al also analysed 107 gastric cancer patient tissue samples by immunohistochemistry to elucidate the role of SOCS3 expression in gastric cancer, and found that SOCS3 was the best indicator for lymph node metastasis; and thus, further studies are warranted to explore its role as a predictor of lymph node metastasis in gastric cancer (90).

The role of STAT3 in inflammation-mediated gastric tumorigenesis has also been extensively explored. A study using loss- and gain-of-function of STAT3 mice in a colitisassociated cancer (CAC) model showed that gp130/STAT3 signaling cascade provides a link between inflammation and gastrointestinal cancers. STAT3 was found to function in tumor progression by promoting intestinal epithelial cell (IEC) survival and proliferation through G1 and G2/M cell-cycle progression (91). Furthermore, it was shown that low-grade intraepithelial lesions in Stat3-deficient mice progress to advanced tubular tumors, thus, affirming the critical role of STAT3 in IEC proliferation and survival in CAC carcinogenesis (92). Additionally, more aggressive tumors have been observed in relation to STAT3 activation, either by epithelial-specific SOCS3 ablation or introduction of SOCS3 binding-deficient gp130 ${ }^{\mathrm{Y} 757 \mathrm{~F}}$ mutation $(93,94)$. These reports have provided valuable insights into STAT3-driven inflammation and gastric cancer (94).

Therapeutic potential of JAK/STAT inhibitors in human cancers. Constitutive activation of JAK/STAT signaling is a common occurrence in human cancers. Tumors may arise either due to an increased autocrine/paracrine cytokine signaling via the associated receptors or due to an increased transcription of downstream STAT-dependent target genes, such as prosurvival Bcl-2 family members, angiogenic factors (HIF-1 $\alpha$ ), inflammation promoting genes (IL-10, TGF- $\beta, \mathrm{COX}-2)$ or metastasis regulators (MMP1/3/9, ICAM-1) (77,95-97).

Tocilizumab, a monoclonal antibody against IL-6 receptors, has proven to be effective in inflammatory conditions, including Rheumatoid arthritis as well as Castleman's disease, with recent clinical trials testing the efficacy of this antibody in the context of cancers (98-100). Tocilizumab has been tested for its efficacy in various IL-6-driven cancer models for largecell carcinoma of the lung, ovarian cancer as well as pancreatic ductal adenocarcinoma (101-103). In vitro and in vivo studies have shown that treatment of these tumors with this IL-6 receptor antibody significantly decreases the size of the tumor mass as well as invasion/metastasis, and ongoing clinical trials are testing its efficacy in patients with recurrent ovarian cancer and chronic lymphocytic leukemia $(104,105)$. In addition, the IL-6 ligand antibody CNTO-328 is currently under phase I/II clinical trials for myeloma and prostate cancer (106-108).

In myeloproliferative neoplasms involving activating somatic mutations in $J A K 1 / 2$, clinical trials of JAK inhibi- 


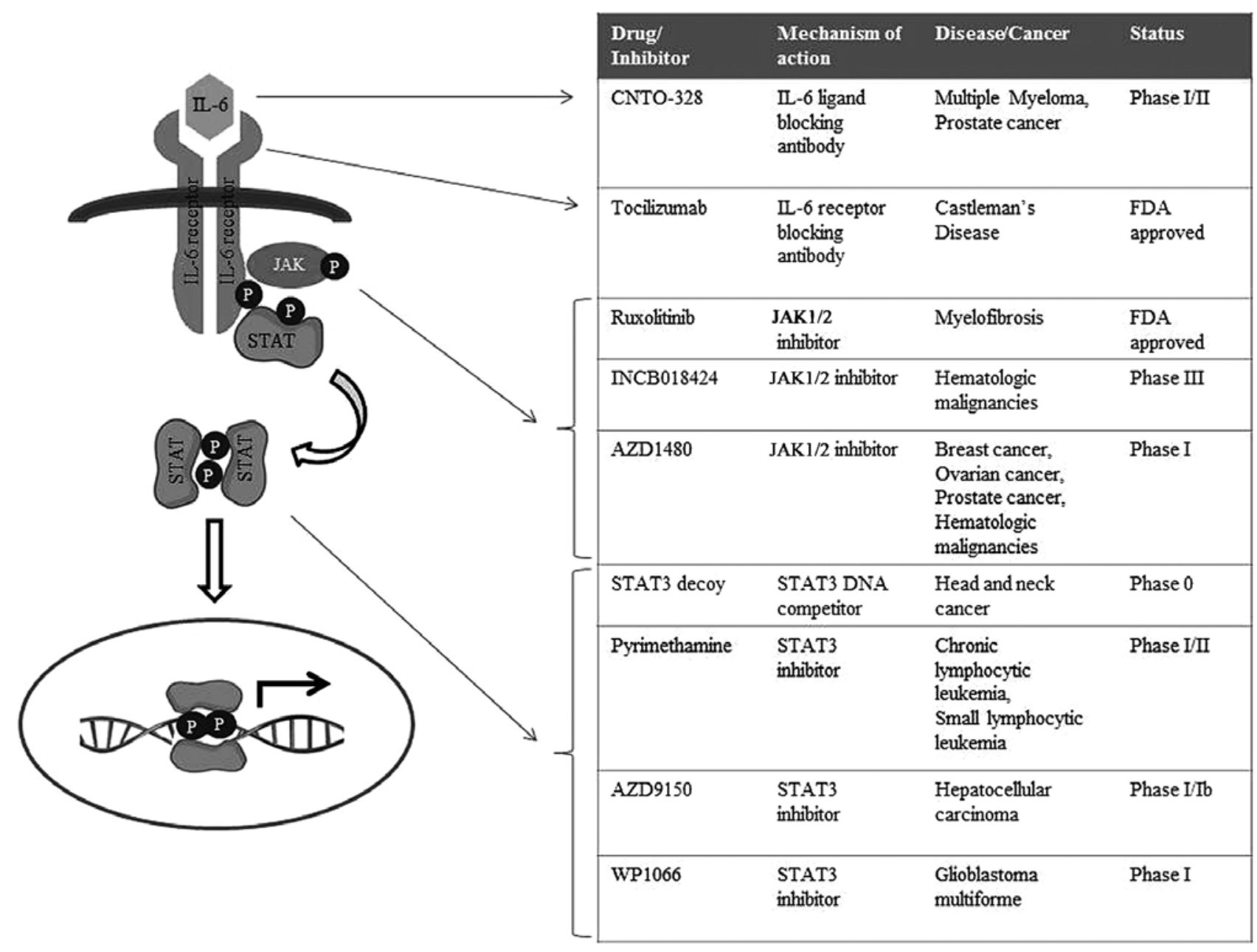

Figure 3. Ongoing clinical trials of cancer drugs that target the components of the JAK/STAT pathway.

tors have demonstrated a significant improvement in patient survival rates, with the JAK1/2 inhibitor ruxolitinib becoming the first FDA approved drug for the treatment of intermediate-/ high-risk myelofibrosis clinically $(109,110)$. Moreover, the JAK inhibitor AG490 has been successful in reducing tumor growth both in vitro and in vivo models of relapsed B-cell leukemias (111). Orally administered JAK1/2 inhibitors, such as INCB018424, are currently in phase III clinical trials for myeloproliferative disorders where it has shown several clinical improvements, including reduction in splenomegaly, discomfort and night sweats (112). Additionally, the JAK1/2 inhibitor AZD1480 has shown to reduce tumor growth and aggressiveness in the xenograft models of IL6-mediated breast, ovarian and prostate cancers, and thus, ongoing clinical trials are exploring its potential in patients (113).

Due to their multifaceted roles as transcription factors, STAT family proteins are vital mediators of tumorigenesis, in the context of both solid tumors as well as hematopoietic malignancies. Hence, inhibitors abrogating STAT signaling are also extensively being studied (114-116). A STAT3 decoy, a double-stranded DNA containing STAT3-binding site, has been shown to successfully act in sequestering dimeric STAT3 away from its endogenous targets (117). Preliminary results with the STAT3 decoy in head and neck cancer showed that it successfully results in the apoptosis of cancer cells and a reduction in tumor growth; and thus, this decoy is being tested clinically in patients with head and neck squamous carcinoma $(118,119)$. Peptidomemetics and designed small molecules specifically targeting STAT3 have also shown promising outcomes in preclinical acute cancer models for human breast cancer, pancreatic cancer, prostate cancer and non-small cell lung cancer, as well as in hematopoietic disorders such as acute myeloid leukemia (120-122). Nifuroxazide, which was initially identified as a treatment drug for diarrhea, was shown to effectively inhibit the survival of multiple myeloma cells by suppressing JAK2 and TYK2 directly (123). Similarly, the malarial drug pyrimethamine was found to inhibit STAT3, and is currently under investigation as a treatment option for chronic lymphocytic leukemia and small lymphocytic leukemia (124).

\section{Conclusion}

As compared to other cancer types, a large proportion of gastric carcinoma patients even after curative surgery suffer from relapse and secondary diseases. The use of histopathological features such as depth of primary tumor and lymph node metastasis status have improved prognosis in these cancers. However, the need for better and new molecular markers still exists. Ongoing studies on important signaling 
molecules, including ErbB, VEGFR and PI3K/mTOR/Akt, as potential prognostic markers have not yet led to translation into clinical practices hitherto.

Studies have demonstrated dysregulated JAK/STAT signaling in patient cohorts with gastric carcinoma. In particular, aberrant STAT3 expression has been implicated in gastric adenocarcinoma patients, making STAT3 a promising candidate as a prognostic marker in gastric cancers $(79,85,125,126)$. In gastric cancer, the abnormal STAT3 expression not only contributes to cancer cell proliferation and survival, but also functions in promoting inflammation, EMT transition and metastasis $(94,97,127,128)$. Various in vitro and in vivo studies have confirmed the role of STAT3 in the precancerous pathology of the stomach, indicating that STAT3 may serve as a useful prognostic/diagnostic biomarker for the early detection of gastric cancer and that limiting STAT3 activity could help prevent malignancy (125). Altogether, these findings suggest that targeting the aberrant JAK/STAT signaling in gastric carcinoma may hold great potential as a novel therapeutic intervention for the treatment of patients with gastric cancer; and that the drugs/inhibitors of JAK/STAT cascade currently in clinical trials for solid tumors and hematopoietic malignancies (Fig. 3) should also be tested for their efficacy as therapeutics in gastric carcinoma.

\section{Acknowledgements}

The authors would like to thank Ms. Song Lin Bay from the Department of Anatomy, National University of Singapore for technical assistance. This study was supported by the NUS start-up grant R-181-000-142-133.

\section{References}

1. Jemal A, Bray F, Center MM, Ferlay J, Ward E and Forman D: Global cancer statistics. CA Cancer J Clin 61: 69-90, 2011.

2. Torre LA, Bray F, Siegel RL, Ferlay J, Lortet-Tieulent J and Jemal A: Global cancer statistics, 2012. CA Cancer J Clin 65: 87-108, 2015.

3. Parkin DM: The global health burden of infection-associated cancers in the year 2002. Int J Cancer 118: 3030-3044, 2006.

4. Fock KM: Review article: The epidemiology and prevention of gastric cancer. Aliment Pharmacol Ther 40: 250-260, 2014.

5. Owen DA: Normal histology of the stomach. Am J Surg Pathol 10: 48-61, 1986.

6. Dicken BJ, Bigam DL, Cass C, Mackey JR, Joy AA and Hamilton SM: Gastric adenocarcinoma: Review and considerations for future directions. Ann Surg 241: 27-39, 2005.

7. Kelley JR and Duggan JM: Gastric cancer epidemiology and risk factors. J Clin Epidemiol 56: 1-9, 2003.

8. Allum WH: Tumours of the stomach. Surgery 29: 575-580, 2011.

9. Gilligan CJ, Lawton GP, Tang LH, West AB and Modlin IM: Gastric carcinoid tumors: The biology and therapy of an enigmatic and controversial lesion. Am J Gastroenterol 90: 338-352, 1995.

10. Lauren P: The two histological main types of gastric carcinoma: Diffuse and so-called intestinal-type carcinoma. An attempt at a histo-clinical classification. Acta Pathol Microbiol Scand 64 31-49, 1965.

11. Munoz N, Correa P, Cuello C and Duque E: Histologic types of gastric carcinoma in high- and low-risk areas. Int J Cancer 3: 809-818, 1968

12. Crew KD and Neugut AI: Epidemiology of gastric cancer. World J Gastroenterol 12: 354-362, 2006.

13. Davessar K, Pezzullo JC, Kessimian N, Hale JH and Jauregui HO Gastric adenocarcinoma: Prognostic significance of several pathologic parameters and histologic classifications. Hum Pathol 21: 325-332, 1990.

14. Ming SC: Gastric carcinoma. A pathobiological classification. Cancer 39: 2475-2485, 1977.
15. Rugge M, Capelle LG, Cappellesso R, Nitti D and Kuipers EJ: Precancerous lesions in the stomach: From biology to clinical patient management. Best Pract Res Clin Gastroenterol 27: 205-223, 2013.

16. Forman D and Burley VJ: Gastric cancer: Global pattern of the disease and an overview of environmental risk factors. Best Pract Res Clin Gastroenterol 20: 633-649, 2006.

17. Pizzi M, Saraggi D, Fassan M, Megraud F, Di Mario F and Rugge M: Secondary prevention of epidemic gastric cancer in the model of Helicobacter pylori-associated gastritis. Dig Dis 32: 265-274, 2014

18. Levi E, Sochacki P, Khoury N, Patel BB and Majumdar AP: Cancer stem cells in Helicobacter pylori infection and aging: Implications for gastric carcinogenesis. World J Gastrointest Pathophysiol 5: 366-372, 2014.

19. Compare D, Rocco A and Nardone G: Risk factors in gastric cancer. Eur Rev Med Pharmacol Sci 14: 302-308, 2010.

20. Sheh A, Ge Z, Parry NM, Muthupalani S, Rager JE, Raczynski AR, Mobley MW, McCabe AF, Fry RC, Wang TC, et al: $17 \beta$-estradiol and tamoxifen prevent gastric cancer by modulating leukocyte recruitment and oncogenic pathways in Helicobacter pylori-infected INS-GAS male mice. Cancer Prev Res (Phila) 4: 1426-1435, 2011.

21. Bertuccio P, Chatenoud L, Levi F, Praud D, Ferlay J, Negri E, Malvezzi M and La Vecchia C: Recent patterns in gastric cancer: a global overview. Int J Cancer 125: 666-673, 2009.

22. Curado M-P, Edwards B, Shin HR, et al: Cancer incidence in five continents. Vol. IX. IARC Press, International Agency for Research on Cancer, Lyon, 2007.

23. Howson CP, Hiyama T and Wynder EL: The decline in gastric cancer: Epidemiology of an unplanned triumph. Epidemiol Rev 8: 1-27, 1986

24. De Stefani E, Correa P, Boffetta P, Deneo-Pellegrini H, Ronco AL and Mendilaharsu M: Dietary patterns and risk of gastric cancer: a case-control study in Uruguay. Gastric cancer 7: 211-220, 2004.

25. Wadhwa R, Song S, Lee JS, Yao Y, Wei Q and Ajani JA: Gastric cancer-molecular and clinical dimensions. Nat Rev Clin Oncol 10: 643-655, 2013

26. Deng N, Goh LK, Wang H, Das K, Tao J, Tan IB, Zhang S, Lee M, Wu J, Lim KH, et al: A comprehensive survey of genomic alterations in gastric cancer reveals systematic patterns of molecular exclusivity and co-occurrence among distinct therapeutic targets. Gut 61: 673-684, 2012.

27. Zhang J, Chiodini R, Badr A and Zhang G: The impact of next-generation sequencing on genomics. J Genet Genomics 38: 95-109, 2011.

28. Grada A and Weinbrecht K: Next-generation sequencing: Methodology and application. J Invest Dermatol 133: e11, 2013.

29. Lee J, van Hummelen P, Go C, Palescandolo E, Jang J, Park HY, Kang SY, Park JO, Kang WK, MacConaill L, et al: Highthroughput mutation profiling identifies frequent somatic mutations in advanced gastric adenocarcinoma. PLoS One 7: e38892, 2012.

30. Zang ZJ, Cutcutache I, Poon SL, Zhang SL, McPherson JR, Tao J, Rajasegaran V, Heng HL, Deng N, Gan A, et al: Exome sequencing of gastric adenocarcinoma identifies recurrent somatic mutations in cell adhesion and chromatin remodeling genes. Nat Genet 44: 570-574, 2012.

31. Kim MA, Lee HS, Lee HE, Jeon YK, Yang HK and Kim WH: EGFR in gastric carcinomas: Prognostic significance of protein overexpression and high gene copy number. Histopathology 52: 738-746, 2008.

32. Langer R, Von Rahden BH, Nahrig J, Von Weyhern C, Reiter R, Feith M, Stein HJ, Siewert JR, Höfler H and Sarbia M: Prognostic significance of expression patterns of c-erbB-2, p53, p16I ${ }^{\mathrm{NK} 4 \mathrm{~A}}$ p2 $7^{\mathrm{KIP} 1}$, cyclin D1 and epidermal growth factor receptor in oesophageal adenocarcinoma: A tissue microarray study. J Clin Pathol 59: 631-634, 2006.

33. Dulak AM, Schumacher SE, van Lieshout J, Imamura Y, Fox C, Shim B, Ramos AH, Saksena G, Baca SC, Baselga J, et al: Gastrointestinal adenocarcinomas of the esophagus, stomach, and colon exhibit distinct patterns of genome instability and oncogenesis. Cancer Res 72: 4383-4393, 2012.

34. Waddell T, Chau I, Cunningham D, Gonzalez D, Okines AF, Okines C, Wotherspoon A, Saffery C, Middleton G, Wadsley J, et al: Epirubicin, oxaliplatin, and capecitabine with or without panitumumab for patients with previously untreated advanced oesophagogastric cancer (REAL3): A randomised, open-label phase 3 trial. Lancet Oncol 14: 481-489, 2013.

35. Gravalos $\mathrm{C}$ and Jimeno A: HER2 in gastric cancer: a new prognostic factor and a novel therapeutic target. Ann Oncol 19: 1523-1529, 2008. 
36. Yano T, Doi T, Ohtsu A, Boku N, Hashizume K, Nakanishi M and Ochiai A: Comparison of HER2 gene amplification assessed by fluorescence in situ hybridization and HER2 protein expression assessed by immunohistochemistry in gastric cancer. Oncol Rep 15: 65-71, 2006.

37. Bang YJ, Van Cutsem E, Feyereislova A, Chung HC, Shen L, Sawaki A, Lordick F, Ohtsu A, Omuro Y, Satoh T, et al; ToGA Trial Investigators: Trastuzumab in combination with chemotherapy versus chemotherapy alone for treatment of HER2-positive advanced gastric or gastro-oesophageal junction cancer (ToGA): A phase 3, open-label, randomised controlled trial. Lancet 376: 687-697, 2010.

38. Hayashi M, Inokuchi M, Takagi Y, Yamada H, Kojima K, Kumagai J, Kawano T and Sugihara K: High expression of HER3 is associated with a decreased survival in gastric cancer. Clin Cancer Res 14: 7843-7849, 2008.

39. Zhang XL, Yang YS, Xu DP, Qu JH, Guo MZ, Gong Y and Huang J: Comparative study on overexpression of HER2/neu and HER 3 in gastric cancer. World J Surg 33: 2112-2118, 2009.

40. Yang W, Raufi A and Klempner SJ: Targeted therapy for gastric cancer: Molecular pathways and ongoing investigations. Biochim Biophys Acta 1846: 232-237, 2014.

41. Kim SE, Shim KN, Jung SA, Yoo K and Lee JH: The clinicopathological significance of tissue levels of hypoxia-inducible factor-1alpha and vascular endothelial growth factor in gastric cancer. Gut Liver 3: 88-94, 2009.

42. Cabuk D, Basaran G, Celikel C, Dane F, Yumuk PF, Iyikesici MS, Ekenel M and Turhal NS: Vascular endothelial growth factor, hypoxia-inducible factor 1 alpha and CD34 expressions in earlystage gastric tumors: Relationship with pathological factors and prognostic impact on survival. Oncology 72: 111-117, 2007.

43. Jüttner S, Wissmann C, Jöns T, Vieth M, Hertel J, Gretschel S, Schlag PM, Kemmner W and Höcker M: Vascular endothelial growth factor-D and its receptor VEGFR-3: Two novel independent prognostic markers in gastric adenocarcinoma. J Clin Oncol 24: 228-240, 2006.

44. Shah MA, Ramanathan RK, Ilson DH, Levnor A, D'Adamo D, O'Reilly E, Tse A, Trocola R, Schwartz L, Capanu M, et al: Multicenter phase II study of irinotecan, cisplatin, and bevacizumab in patients with metastatic gastric or gastroesophageal junction adenocarcinoma. J Clin Oncol 24: 5201-5206, 2006.

45. Ohtsu A, Shah MA, Van Cutsem E, Rha SY, Sawaki A, Park SR, Lim HY, Yamada Y, Wu J, Langer B, et al: Bevacizumab in combination with chemotherapy as first-line therapy in advanced gastric cancer: A randomized, double-blind, placebo-controlled phase III study. J Clin Oncol 29: 3968-3976, 2011.

46. Fuchs CS, Tomasek J, Yong CJ, Dumitru F, Passalacqua R, Goswami C, Safran H, dos Santos LV, Aprile G, Ferry DR, et al; REGARD Trial Investigators: Ramucirumab monotherapy for previously treated advanced gastric or gastro-oesophageal junction adenocarcinoma (REGARD): An international, randomised, multicentre, placebo-controlled, phase 3 trial. Lancet 383: 31-39, 2014

47. Su X, Zhan P, Gavine PR, Morgan S, Womack C, Ni X, Shen D, Bang YJ, Im SA, Ho Kim W, et al: FGFR2 amplification has prognostic significance in gastric cancer: Results from a large international multicentre study. Br J Cancer 110: 967-975, 2014.

48. Xie L, Su X, Zhang L, Yin X, Tang L, Zhang X, Xu Y, Gao Z, Liu K, Zhou M, et al: FGFR2 gene amplification in gastric cancer predicts sensitivity to the selective FGFR inhibitor AZD4547. Clin Cancer Res 19: 2572-2583, 2013.

49. Vivanco I and Sawyers CL: The phosphatidylinositol 3-Kinase AKT pathway in human cancer. Nat Rev Cancer 2: 489-501, 2002

50. Liu JF, Zhou XK, Chen JH, Yi G, Chen HG, Ba MC, Lin SQ and Qi YC: Up-regulation of PIK3CA promotes metastasis in gastric carcinoma. World J Gastroenterol 16: 4986-4991, 2010.

51. Shi J, Yao D, Liu W, Wang N, Lv H, Zhang G, Ji M, Xu L, He N, Shi B, et al: Highly frequent PIK3CA amplification is associated with poor prognosis in gastric cancer. BMC Cancer 12: 50, 2012.

52. Dong M, Phan AT and Yao JC: New strategies for advanced neuroendocrine tumors in the era of targeted therapy. Clin Cancer Res 18: 1830-1836, 2012.

53. Ohtsu A, Ajani JA, Bai YX, Bang YJ, Chung HC, Pan HM, Sahmoud T, Shen L, Yeh KH, Chin K, et al: Everolimus for previously treated advanced gastric cancer: Results of the randomized, double-blind, phase III GRANITE-1 study. J Clin Oncol 31: 3935-3943, 2013.

54. Yang W, Raufi A and Klempner SJ: Targeted therapy for gastric cancer: Molecular pathways and ongoing investigations. Biochim Biophys Acta 1846: 232-237, 2014.
55. Proserpio I, Rausei S, Barzaghi S, Frattini F, Galli F, Iovino D, Rovera F, Boni L, Dionigi G and Pinotti G: Multimodal treatment of gastric cancer. World J Gastrointest Surg 6: 55-58, 2014.

56. Darnell JE Jr, Kerr IM and Stark GR: Jak-STAT pathways and transcriptional activation in response to IFNs and other extracellular signaling proteins. Science 264: 1415-1421, 1994.

57. Aaronson DS and Horvath CM: A road map for those who don't know JAK-STAT. Science 296: 1653-1655, 2002.

58. Rawlings JS, Rosler KM and Harrison DA: The JAK/STAT signaling pathway. J Cell Sci 117: 1281-1283, 2004.

59. Harrison DA: The Jak/STAT pathway. Cold Spring Harb Perspect Biol 4: 4, 2012

60. Kiu H and Nicholson SE: Biology and significance of the JAK/ STAT signalling pathways. Growth Factors 30: 88-106, 2012.

61. Espert L, Dusanter-Fourt I and Chelbi-Alix MK: Negative regulation of the JAK/STAT: Pathway implication in tumorigenesis Bull Cancer 92: 845-857, 2005 (In French).

62. Valentino L and Pierre J: JAK/STAT signal transduction: Regulators and implication in hematological malignancies. Biochem Pharmacol 71: 713-721, 2006.

63. Kisseleva T, Bhattacharya S, Braunstein J and Schindler CW: Signaling through the JAK/STAT pathway, recent advances and future challenges. Gene 285: 1-24, 2002.

64. Li WX: Canonical and non-canonical JAK-STAT signaling. Trends Cell Biol 18: 545-551, 2008.

65. Sansone P and Bromberg J: Targeting the interleukin-6/Jak/stat pathway in human malignancies. J Clin Oncol 30: 1005-1014, 2012.

66. Scott LM: The JAK2 exon 12 mutations: A comprehensive review. Am J Hematol 86: 668-676, 2011.

67. Kralovics R, Passamonti F, Buser AS, Teo SS, Tiedt R, Passweg JR, Tichelli A, Cazzola M and Skoda RC: A gain-offunction mutation of JAK2 in myeloproliferative disorders. N Engl J Med 352: 1779-1790, 2005.

68. Rebouissou S, Amessou M, Couchy G, Poussin K, Imbeaud S, Pilati C, Izard T, Balabaud C, Bioulac-Sage P and Zucman-Rossi J: Frequent in-frame somatic deletions activate gp130 in inflammatory hepatocellular tumours. Nature 457: 200-204, 2009.

69. Lee H, Deng J, Kujawski M, Yang C, Liu Y, Herrmann A, Kortylewski M, Horne D, Somlo G, Forman S, et al: STAT3induced S1PR1 expression is crucial for persistent STAT3 activation in tumors. Nat Med 16: 1421-1428, 2010.

70. Oh ST, Simonds EF, Jones C, Hale MB, Goltsev Y, Gibbs KD Jr, Merker JD, Zehnder JL, Nolan GP and Gotlib J: Novel mutations in the inhibitory adaptor protein LNK drive JAK-STAT signaling in patients with myeloproliferative neoplasms. Blood 116: 988-992, 2010.

71. Veeriah S, Brennan C, Meng S, Singh B, Fagin JA, Solit DB, Paty PB, Rohle D, Vivanco I, Chmielecki J, et al: The tyrosine phosphatase PTPRD is a tumor suppressor that is frequently inactivated and mutated in glioblastoma and other human cancers. Proc Natl Acad Sci USA 106: 9435-9440, 2009.

72. Bromberg JF, Wrzeszczynska MH, Devgan G, Zhao Y, Pestell RG, Albanese C and Darnell JE Jr: Stat 3 as an oncogene. Cell 98: 295-303, 1999.

73. Stephanou A, Brar BK, Knight RA and Latchman DS: Opposing actions of STAT- 1 and STAT- 3 on the Bcl-2 and Bcl-x promoters. Cell Death Differ 7: 329-330, 2000.

74. O'Connor DS, Grossman D, Plescia J, Li F, Zhang H, Villa A, Tognin S, Marchisio PC and Altieri DC: Regulation of apoptosis at cell division by $\mathrm{p} 34 \mathrm{cdc} 2$ phosphorylation of survivin. Proc Natl Acad Sci USA 97: 13103-13107, 2000.

75. Wendt MK, Balanis N, Carlin CR and Schiemann WP: STAT3 and epithelial-mesenchymal transitions in carcinomas. JAK-STAT 3: e28975, 2014.

76. Teng Y, Ross JL and Cowell JK: The involvement of JAK-STAT3 in cell motility, invasion, and metastasis. JAK-STAT 3: e28086, 2014.

77. Wei D, Le X, Zheng L, Wang L, Frey JA, Gao AC, Peng Z, Huang S, Xiong HQ, Abbruzzese JL, et al: Stat3 activation regulates the expression of vascular endothelial growth factor and human pancreatic cancer angiogenesis and metastasis. Oncogene 22: 319-329, 2003.

78. Kujawski M, Kortylewski M, Lee H, Herrmann A, Kay H and Yu H: Stat 3 mediates myeloid cell-dependent tumor angiogenesis in mice. J Clin Invest 118: 3367-3377, 2008.

79. Gong W, Wang L, Yao JC, Ajani JA, Wei D, Aldape KD, Xie K, Sawaya R and Huang S: Expression of activated signal transducer and activator of transcription 3 predicts expression of vascular endothelial growth factor in and angiogenic phenotype of human gastric cancer. Clin Cancer Res 11: 1386-1393, 2005. 
80. Wang T, Niu G, Kortylewski M, Burdelya L, Shain K, Zhang S, Bhattacharya R, Gabrilovich D, Heller R, Coppola D, et al Regulation of the innate and adaptive immune responses by Stat-3 signaling in tumor cells. Nat Med 10: 48-54, 2004.

81. Wang F, Arun P, Friedman J, Chen Z and Van Waes C: Current and potential inflammation targeted therapies in head and neck cancer. Curr Opin Pharmacol 9: 389-395, 2009.

82. Niu G, Wright KL, Huang M, Song L, Haura E, Turkson J, Zhang S, Wang T, Sinibaldi D, Coppola D, et al: Constitutive Stat 3 activity up-regulates VEGF expression and tumor angiogenesis. Oncogene 21: 2000-2008, 2002.

83. Wang Z, Si X, Xu A, Meng X, Gao S, Qi Y, Zhu L, Li T, Li W and Dong L: Activation of STAT3 in human gastric cancer cells via interleukin (IL)-6-type cytokine signaling correlates with clinical implications. PLoS One 8: e75788, 2013.

84. Giraud AS, Menheniott TR and Judd LM: Targeting STAT3 in gastric cancer. Expert Opin Ther Targets 16: 889-901, 2012.

85. Kanda N, Seno H, Konda Y, Marusawa H, Kanai M, Nakajima T, Kawashima T, Nanakin A, Sawabu T, Uenoyama Y, et al: STAT3 is constitutively activated and supports cell survival in association with survivin expression in gastric cancer cells. Oncogene 23: 4921-4929, 2004

86. Sekikawa A, Fukui H, Fujii S, Ichikawa K, Tomita S, Imura J, Chiba T and Fujimori T: REG Ialpha protein mediates an antiapoptotic effect of STAT3 signaling in gastric cancer cells Carcinogenesis 29: 76-83, 2008.

87. Jackson CB, Judd LM, Menheniott TR, Kronborg I, Dow C, Yeomans ND, Boussioutas A, Robb L and Giraud AS: Augmented gp130-mediated cytokine signalling accompanies human gastric cancer progression. J Pathol 213: 140-151, 2007.

88. Kim DY, Cha ST, Ahn DH, Kang HY, Kwon CI, Ko KH, Hwang SG, Park PW, Rim KS and Hong SP: STAT3 expression in gastric cancer indicates a poor prognosis. J Gastroenterol Hepatol 24: 646-651, 2009.

89. Deng JY, Sun D, Liu XY, Pan Y and Liang H: STAT-3 correlates with lymph node metastasis and cell survival in gastric cancer. World J Gastroenterol 16: 5380-5387, 2010.

90. Deng J, Jiao X, Liu H, Wu L, Zhang R, Wang B, Pan Y, Hao X and Liang $\mathrm{H}$ : Lymph node metastasis is mediated by suppressor of cytokine signaling-3 in gastric cancer. Tumour Biol 34 3627-3636, 2013.

91. Bollrath J, Phesse TJ, von Burstin VA, Putoczki T, Bennecke M, Bateman T, Nebelsiek T, Lundgren-May T, Canli O, Schwitalla S, et al: gp130-mediated Stat3 activation in enterocytes regulates cell survival and cell-cycle progression during colitis-associated tumorigenesis. Cancer Cell 15: 91-102, 2009.

92. Grivennikov S, Karin E, Terzic J, Mucida D, Yu GY, Vallabhapurapu S, Scheller J, Rose-John S, Cheroutre H, Eckmann L, et al: IL-6 and Stat 3 are required for survival of intestinal epithelial cells and development of colitis-associated cancer. Cancer Cell 15: 103-113, 2009.

93. Rigby RJ, Simmons JG, Greenhalgh CJ, Alexander WS and Lund PK: Suppressor of cytokine signaling 3 (SOCS3) limits damage-induced crypt hyper-proliferation and inflammationassociated tumorigenesis in the colon. Oncogene 26: 4833-4841, 2007.

94. Ernst M and Putoczki TL: Stat3: Linking inflammation to (gastrointestinal) tumourigenesis. Clin Exp Pharmacol Physio 39: 711-718, 2012

95. Leonard WJ: Role of Jak kinases and STATs in cytokine signal transduction. Int J Hematol 73: 271-277, 2001.

96. Ihle JN: The Stat family in cytokine signaling. Curr Opin Cell Biol 13: 211-217, 2001.

97. Carpenter RL and Lo HW: STAT3 target genes relevant to human cancers. Cancers (Basel) 6: 897-925, 2014

98. Nishimoto $\mathrm{N}$ and Kishimoto T: Interleukin 6: From bench to bedside. Nat Clin Pract Rheumatol 2: 619-626, 2006.

99. Nakashima $Y$, Kondo M, Harada $H$, Horiuchi T, Ishinishi T, Jojima H, Kuroda K, Miyahara H, Nagamine R, Nakashima H, et al: Clinical evaluation of tocilizumab for patients with active rheumatoid arthritis refractory to anti-TNF biologics: tocilizumab in combination with methotrexate. Mod Rheumatol 20 : $343-352,2010$

100. Garnero P, Thompson E, Woodworth T and Smolen JS: Rapid and sustained improvement in bone and cartilage turnover markers with the anti-interleukin-6 receptor inhibitor tocilizumab plus methotrexate in rheumatoid arthritis patients with an inadequate response to methotrexate: Results from a substudy of the multicenter double-blind, placebo-controlled trial of tocilizumab in inadequate responders to methotrexate alone. Arthritis Rheum 62: $33-43,2010$.
101. Ando K, Takahashi F, Motojima S, Nakashima K, Kaneko N, Hoshi K and Takahashi K: Possible role for tocilizumab, an anti-interleukin- 6 receptor antibody, in treating cancer cachexia. J Clin Oncol 31: e69-e72, 2013.

102. Isobe A, Sawada K, Kinose Y, Ohyagi-Hara C, Nakatsuka E, Makino H, Ogura T, Mizuno T, Suzuki N, Morii E, et al: Interleukin 6 receptor is an independent prognostic factor and a potential therapeutic target of ovarian cancer. PLoS One 10: e0118080, 2015.

103. Goumas FA, Holmer R, Egberts JH, et al: Inhibition of IL-6 signaling significantly reduces primary tumor growth and recurrencies in orthotopic xenograft models of pancreatic cancer. Int J Cancer: Jan 21, 2015 (Epub ahead of print). doi: 10.1002/ ijc. 29445.

104. Dijkgraaf EM, Welters MJ, Nortier JW, van der Burg SH and Kroep JR: Interleukin-6/interleukin-6 receptor pathway as a new therapy target in epithelial ovarian cancer. Curr Pharm Des 18: 3816-3827, 2012.

105. Yao X, Huang J, Zhong H, Shen N, Faggioni R, Fung M and Yao Y: Targeting interleukin-6 in inflammatory autoimmune diseases and cancers. Pharmacol Ther 141: 125-139, 2014.

106. Wallner L, Dai J, Escara-Wilke J, Zhang J, Yao Z, Lu Y, Trikha M, Nemeth JA, Zaki MH and Keller ET: Inhibition of interleukin-6 with CNTO328, an anti-interleukin-6 monoclonal antibody, inhibits conversion of androgen-dependent prostate cancer to an androgen-independent phenotype in orchiectomized mice. Cancer Res 66: 3087-3095, 2006.

107. Puchalski T, Prabhakar U, Jiao Q, Berns B and Davis HM Pharmacokinetic and pharmacodynamic modeling of an antiinterleukin-6 chimeric monoclonal antibody (siltuximab) in patients with metastatic renal cell carcinoma. Clin Cancer Res16: 1652-1661, 2010.

108. Dorff TB, Goldman B, Pinski JK, Mack PC, Lara PN Jr, Van Veldhuizen PJ Jr, Quinn DI, Vogelzang NJ, Thompson IM Jr and Hussain MH: Clinical and correlative results of SWOG S0354: a phase II trial of CNTO328 (siltuximab), a monoclonal antibody against interleukin-6, in chemotherapy-pretreated patients with castration-resistant prostate cancer. Clin Cancer Res 16: 3028-3034, 2010

109. Mascarenhas J and Hoffman R: Ruxolitinib: the first FDA approved therapy for the treatment of myelofibrosis. Clin Cancer Res 18: 3008-3014, 2012.

110. Ganetsky A: Ruxolitinib: A new treatment option for myelofibrosis. Pharmacotherapy 33: 84-92, 2013

111. Meydan N, Grunberger T, Dadi H, Shahar M, Arpaia E, Lapidot Z, Leeder JS, Freedman M, Cohen A, Gazit A, et al: Inhibition of acute lymphoblastic leukaemia by a Jak-2 inhibitor. Nature 379: 645-648, 1996.

112. Quintás-Cardama A, Vaddi K, Liu P, Manshouri T, Li J, Scherle PA, Caulder E, Wen X, Li Y, Waeltz P, et al: Preclinical characterization of the selective JAK1/2 inhibitor INCB018424: Therapeutic implications for the treatment of myeloproliferative neoplasms. Blood 115: 3109-3117, 2010.

113. Hedvat M, Huszar D, Herrmann A, Gozgit JM, Schroeder A, Sheehy A, Buettner R, Proia D, Kowolik CM, Xin H, et al: The JAK2 inhibitor AZD1480 potently blocks Stat 3 signaling and oncogenesis in solid tumors. Cancer Cell 16: 487-497, 2009.

114. Munoz J, Dhillon N, Janku F, Watowich SS and Hong DS: STAT3 inhibitors: Finding a home in lymphoma and leukemia. Oncologist 19: 536-544, 2014

115. Bar-Natan M, Nelson EA, Xiang $M$ and Frank DA: STAT signaling in the pathogenesis and treatment of myeloid malignancies. JAK-STAT 1: 55-64, 2012.

116. Frank DA: STAT signaling in the pathogenesis and treatment of cancer. Mol Med 5: 432-456, 1999.

117. Sen M, Tosca PJ,Zwayer C, Ryan MJ, Johnson JD, Knostman KA, Giclas PC, Peggins JO, Tomaszewski JE, McMurray TP, et al: Lack of toxicity of a STAT3 decoy oligonucleotide. Cancer Chemother Pharmacol 63: 983-995, 2009.

118. Leong PL, Andrews GA, Johnson DE, Dyer KF, Xi S, Mai JC, Robbins PD, Gadiparthi S, Burke NA, Watkins SF, et al: Targeted inhibition of Stat 3 with a decoy oligonucleotide abrogates head and neck cancer cell growth. Proc Natl Acad Sci USA 100: 4138-4143, 2003.

119. Xi S, Gooding WE and Grandis JR: In vivo antitumor efficacy of STAT3 blockade using a transcription factor decoy approach: Implications for cancer therapy. Oncogene 24: 970-979, 2005.

120. Zhao W, Jaganathan S and Turkson J: A cell-permeable Stat3 SH2 domain mimetic inhibits Stat 3 activation and induces antitumor cell effects in vitro. J Biol Chem 285: 35855-35865, 2010 . 
121. Redell MS, Ruiz MJ, Alonzo TA, Gerbing RB and Tweardy DJ: Stat3 signaling in acute myeloid leukemia: Ligand-dependent and -independent activation and induction of apoptosis by a novel small-molecule Stat3 inhibitor. Blood 117: 5701-5709, 2011.

122. Zhang X, Yue P, Fletcher S, Zhao W, Gunning PT and Turkson J: A novel small-molecule disrupts Stat $3 \mathrm{SH} 2$ domain-phosphotyrosine interactions and Stat3-dependent tumor processes. Biochem Pharmacol 79: 1398-1409, 2010.

123. Nelson EA, Walker SR, Kepich A, Gashin LB, Hideshima T, Ikeda H, Chauhan D, Anderson KC and Frank DA: Nifuroxazide inhibits survival of multiple myeloma cells by directly inhibiting STAT3. Blood 112: 5095-5102, 2008.

124. Nelson EA, Sharma SV, Settleman J and Frank DA: A chemical biology approach to developing STAT inhibitors: Molecular strategies for accelerating clinical translation. Oncotarget 2: $518-524,2011$
125. Jackson CB and Giraud AS: STAT3 as a prognostic marker in human gastric cancer. J Gastroenterol Hepatol 24: 505-507, 2009.

126. To KF, Chan MW, Leung WK, Ng EK, Yu J, Bai AH, Lo AW, Chu SH, Tong JH, Lo KW, et al: Constitutional activation of IL-6-mediated JAK/STAT pathway through hypermethylation of SOCS-1 in human gastric cancer cell line. Br J Cancer 91: 1335-1341, 2004.

127. Tye H, Kennedy CL, Najdovska M, McLeod L, McCormack W, Hughes N, Dev A, Sievert W, Ooi CH, Ishikawa TO, et al: STAT3-driven upregulation of TLR2 promotes gastric tumorigenesis independent of tumor inflammation. Cancer Cell 22: 466-478, 2012.

128. Deng J, Liang H, Zhang R, Sun D, Pan Y, Liu Y, Zhang L and Hao X: STAT3 is associated with lymph node metastasis in gastric cancer. Tumour Biol 34: 2791-2800, 2013. 